\title{
Partner selection in market-driven strategic alliances
}

\author{
Saul Klein* \\ Graduate School of Business Administration, University of the Witwatersrand, P.O. Box 98, WITS, 2050 Republic of South Africa \\ kleins@zeus. mgmt. wits. ac. za \\ Chekitan Dev \\ School of Hotel Administration, Cornell University, Itaca, New York, United States of America
}

Received July 1997

\begin{abstract}
How should one select a strategic alliance partner? An answer to this question is provided by extending the literature on symbiotic marketing and focussing attention on market-driven strategic alliances. Such alliances are defined as long-term inter-firm co-operative relationships that add value for the customer. Value is created by providing the advantages of multiple choice purchase options coupled with the convenience of seamless, one-stop-shopping. This means paying attention to customers and competitors in selecting alliance partners. Market-driven strategic alliances are posited to be more successful when usage and firm complementarity levels are correctly matched with the alliance strategy being pursued.
\end{abstract}

* Author to whom correspondence should be addressed.

Much attention has been devoted in recent years to the concept of strategic alliances and the need for businesses to cooperate in order to be competitive (Perlmutter \& Heenan, 1986; Ohmae, 1989; Lewis, 1990; Badaracco, 1991; Byrne, Brandt \& Port, 1993; Rangan \& Yoshino, 1996). The importance of the topic is underscored by the fact that over 20000 new alliances were formed between 1987 and 1992 (Harbison \& Pekar, 1994), and that the number of domestic and crossborder alliances grew more than $25 \%$ annually from 1989 to 1994 (Bleeke \& Ernst, 1995). Global competition, information technology, and increasingly knowledgeable and sophisticated customers all call for new forms of organization. As evidenced by the rash of press reports, in South Africa businesses are turning to alliances in an attempt to overcome the legacy of isolationism and enhance their overall competitiveness.

Pressures to grow have led firms to explore the adoption of mid-range options such as alliances, networks, and other hybrid organization arrangements (Oliver, 1990) as alternatives to more traditional market versus hierarchy options, which have proved problematic. In the ill-fated Allegis experiment in the United States in the mid-1980s, for example, United Airlines attempted to create an integrated travel supply organization with Hertz Car Rental and Hilton International and Westin Hotels, all under common ownership (Willard, Schoenecker \& Kreuger, 1990). Their efforts to achieve synergies and offer greater benefits at lower costs failed. The intended benefits proved difficult to attain and costly to achieve. Alliances represent an alternative structure to capture these elusive benefits at lower cost.

Strategic alliances may be seen as a value-adding effort on the part of the firm, that affords fresh opportunities for building and maintaining competitive advantage (Bucklin \& Sengupta, 1993). Strategic alliances have been viewed from a variety of perspectives, including firm internationalization (Beamish \& Banks, 1987), transaction cost economics (Parkhe, 1993), networks (Miles \& Snow, 1986; Jarillo, 1988), organizational learning (Hamel, 1992), game theory (Parkhe, 1993), developmental processes (Ring \& Van de Ven, 1994), and ethics (Gundlach \& Murphy, 1993). Much of this research has focussed on risk, fixed costs, economies of scale and access to distribution as motivations for alliance formation. What is lacking is an appreciation for the centrality of the customer in the conceptualization, design, and management of strategic alliances. As Peter Francese (1994), President of American Demographics, observed, while an increasing number of companies are forming alliances, they are doing so for the wrong reasons. 'The customer', he lamented, 'is being ignored in all this'.

Based on a market-driven approach to strategic alliances, this article presents an alternative perspective. Such a perspective encompasses both a customer orientation and a competitor focus (compare Day, 1992). Varadarajan \& Rajaratnam's (1986) updated notion of symbiosis, and its feasibility for exploiting strategic growth opportunities, is applied. First, an overview of strategic alliances within the context of symbiotic marketing is presented. Second, a market-driven model of the alliance formation process is developed, focussing on the partner selection question. A contingency model for partner selection is developed, propositions for future research are advanced, and the implications for structuring and managing strategic alliances are discussed. Throughout, the analysis is illustrated with examples drawn from the travel industry, which has witnessed a virtual explosion of alliance activity in the past decade (Business Week, 1992; Dev \& Klein, 1993).

\section{Alliances for competitive advantage}

Until recently, inter-firm relations have been given surprisingly short shrift in marketing (Fisk, 1987), industrial organization economics and organization theory (Thorelli, 1986). For a thorough review of the conceptual foundations of strategic alliances and the role of marketing, see Varadarajan \& Cunningham (1995). In a general sense, strategic alliances are defined in terms of synergistic or symbiotic relationships between two or more independent entities (Adler, 1966); that is, when certain outcomes result from the combining of two firms that would not occur if 
either of the firms were to attempt to achieve the outcome independently. The inability of marketing theory to address such issues of co-operative behaviour was highlighted by Arndt (1979), who argued that theory remains based on a notion of markets where transactions are anonymous and transient. 'Go it alone' and 'Winner take all' are the fundamental, underlying tenets of such a paradigm.

There are two generally accepted motivations for alliance formation: efficiency and effectiveness (Jarillo, 1988). Efficiency objectives of an organization, to 'do things right', involve exploiting cost-reduction opportunities by forming alliances with other companies that have complementary expertise. Effectiveness objectives of an organization, to 'do the right thing', involve market-based motivations to increase market share and size, or to create barriers to competitive entry. By taking a market-driven approach to strategic alliances, efficiency and effectiveness can be addressed simultaneously.

The most important aspect of a strategic alliance, and perhaps the most difficult to define, is the output measure, that is, performance. Success may be measured in terms of longevity (relative to intended duration) or enhanced performance, although measuring performance is notoriously difficult (Anderson, 1990). Suggested performance measures range from qualitative process measures, such as satisfaction with the relationship (Bucklin \& Sengupta, 1993), to quantitative outcome measures, such as number of new products developed or market share gains (Anderson, 1990), to indirect performance indicators, such as spillover effects (Parkhe, 1993). Alliance performance, and consequently the success of the alliance, should be tied to the goals of the alliance at its inception. If an alliance is market-driven, its success should be measured in terms of market effects, such as market share or customer loyalty.

\section{Alliance failure}

While there has been growing interest in the subject of cooperative relationships, there has also been growing disenchantment with them. Some studies suggest that $70 \%$ of joint ventures fall short of expectations or are disbanded (Levine \& Byrne, 1986), while Bleeke \& Ernst (1995) report that nearly $80 \%$ of joint ventures ultimately end in a sale by one of the partners. While some of the disenchantment may be due to unfamiliarity with a new form of business activity, and consequent unrealistic expectations, other factors may also explain alliance failure. Many of these co-operative relationships are costly to maintain and encounter problems in management. Franko (1971), for example, has identified problems with joint ventures and subsequent divorces in multinational companies.

Failure often stems from the types of relationships undertaken, and questions whether the relationships were appropriate from the outset. Are strategic alliances merely the latest management fad or an enduring organizational form that will benefit the modern corporation (Byrne, Brandt \& Port, 1993)? Are alliances formed because they are appropriate, or simply because they are possible? Certainly, the management of such relationships poses unique problems of conceptualization, design and performance evaluation.

A substantial body of literature exists on the factors that contribute to the success of inter-organizational relations.
What is missing is a sound, market-driven basis for partner selection. Although some studies recognize organizational compatibility as an important determinant of alliance success (Spekman \& Sawhney, 1990), most do not focus on the partner selection issue. Varadarajan \& Rajaratnam (1986) argue that customers' buying behaviour, and what such behaviour implies, should be the fundamental issues in partner selection.

\section{Contingency approaches}

In past studies of strategic alliances, contingency theory has been the central theoretical perspective (Varadarajan \& Rajaratnam, 1986; Spekman \& Sawhney, 1990; Bucklin \& Sengupta, 1993; Burgers, Hill \& Kim, 1993). This approach suggests that organizations seeking to improve performance do so within the context of internal and environmental situations that influence their organization. This is the reason why alliances succeed for some businesses, but fail for others (Spekman et al., 1996). Efforts to develop a contingency theory of strategic alliances fall into two main groups: synergy and symbiosis. The synergy-based theorists focus on the antecedents of (or bases for) alliance formation and the consequences (or outcomes) of alliance formation (Spekman \& Sawhney, 1990; Burgers, Hill \& Kim, 1993). The symbiosis-based theorists focus on the alliance itself, delineating issues related to the conditions under which it forms, while also discussing the management of these relationships (Varadarajan \& Rajaratnam, 1986; Parkhe, 1993). A marketdriven approach allows us to merge these two theoretical streams.

\section{Market-driven strategic alliances}

A market-driven strategic alliance is defined as one that adds value for the customer in a competitive context. For example, route and code-sharing agreements between international airlines provide overseas travelers with the advantages of multiple purchase options coupled with the convenience of seamless one-stop-shopping. Added value is imputed from customers' reactions to a combination of goods and services, compared to their reactions to the products of the various firms taken individually. Alliances are successful when customers perceive added value in their relationships with the firm as a result of the alliance, since alliances are fundamentally tools for gaining competitive advantage (Day, 1995). Our focus is on what types of alliances are appropriate for the individual firm under different circumstances.

\section{Stages in alliance formation}

Three stages describe strategic alliance formation within a Strategy-Structure-Performance paradigm (see Figure 1), and failure may occur at any stage. In the first stage, business goals and strategy dictate the type of organizational structure to be used. At this stage, internal and external environmental considerations are paramount; for example demand uncertainty, competitive uncertainty (Burgers, Hill, \& Kim, 1993), resource dependency, transaction costs, life cycle, or strategic orientation (Spekman \& Sawhney, 1990). Failure at this stage results from a poor fit between an organization's strategy and its environment (Miles \& Snow, 1978; Porter, 1980). Different types of alliances are appropriate under 


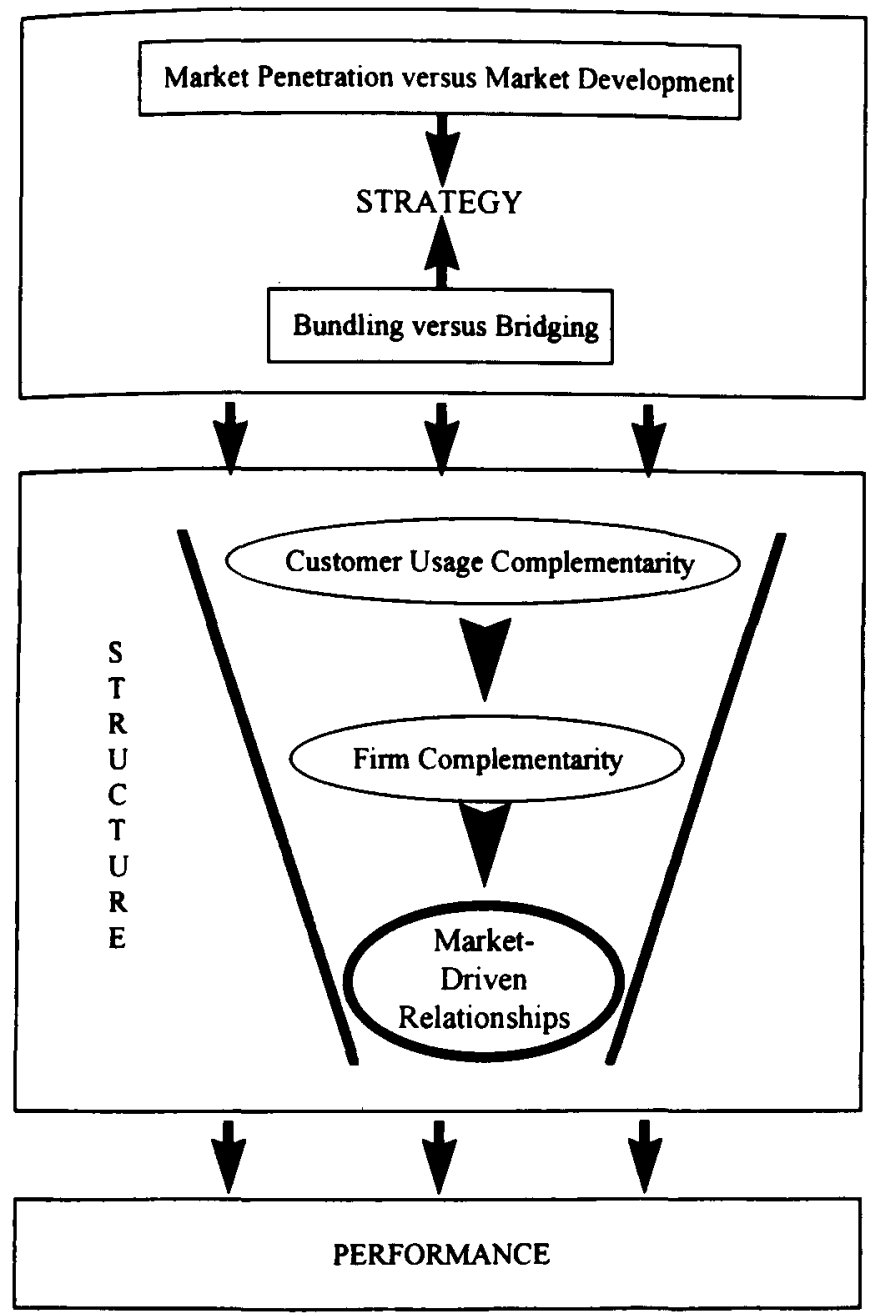

Figure 1 Market-driven strategic alliance process

different conditions, and careful analysis of environmental conditions is required.

\section{Typology}

In listing market-based goals for symbiotic marketing, Varadarajan \& Rajaratnam (1986) expand Ansoff's (1957) typology of growth strategies. The growth opportunities can be distilled to two main market-driven performance goals: market penetration or share, and market development or size. In other words, a firm can increase its sales by doing more business with its existing customers or by creating new customers, or both. These goals can be seen to deliver both greater effectiveness and efficiency.

Alliances, between present or potential competitors, may be intended to 'bridge' gaps in product-market coverage, or to 'bundle' complementary products and services. The concepts of bundling and bridging were suggested by Farquhar $e t$ al. (1992), within the context of branding strategies. Their definitions, however, are not identical to the usage here. Bridging alliances provide value to consumers by expanding the coverage, either geographically or demographically defined, of existing firms. They also reduce costs through scale effects. Bundling alliances provide value to consumers by creating one-stop shopping opportunities, reduced search and transaction costs, and seamless delivery of benefits. Alliances between major airlines and feeder carriers are examples of bridging relationships, while those between airline, hotel and car rental companies are examples of bundling.

Combining the market development versus market penetration goal of the organization with the bundling versus bridging alliance approach, four types of strategic marketing alliances exist (see Table 1). When the goal of the firm is market penetration, and a bridging alliance is chosen, we label this 'Bridge for Share'. In an example, ComAir feeds its short haul point-to-point travelers and British Airways feeds its long-haul travelers into each other's systems. Similarly, in an overseas example, Radisson and SAS Hotels came together in 1994. SAS' main aim was to find a partner with strong marketing skills, and thereby increase its market share. Since the alliance was formed, SAS reservations through Radisson's global reservation system have doubled (Hotels, 1996). Outside the airline industry, bridge for share alliances are also reflected in hospitals' building relationships with feeder clinics.

'Bridge for Size' alliances are based on market development goals, and reflected in the scramble by major international airlines to find partners. SAA has formed alliances with Lufthansa and American Airlines in pursuit of such objectives. Desires to increase the size of their market have also motivated alliances between Delta, Swissair and Singapore Airlines, between United Airlines and Lufthansa, and between Northwest and KLM Royal Dutch Airlines. Since their alliance was formed in late 1989, Singapore Airlines reports that revenue derived from Swissair and Delta grew 10 to $15 \%$ in the 1990/91 financial year over the previous year. Swissair flights from Zurich to Singapore have increased from three to five flights a week due to the alliance with Singapore Airlines (Jennings, 1991).

'Bundle for Share' alliances strive to penetrate existing markets. American Airlines, Hertz Car Rental and Hilton Hotels attempted, but ultimately failed, to get together in the CONFIRM project, targeted at common business travelers. The aim was to cement cross-usage by providing one-stop shopping for complementary products, with ease of use and seamless integration of services. The failure was due to lack of operational fit, in the difficulty in integrating their information technology systems, despite spending several million dollars, and not due to the underlying logic of the venture. A successful example is that between McDonalds and Coca

Table 1 Typology of strategic marketing alliances (with examples)

\begin{tabular}{lll}
\hline & \multicolumn{2}{c}{ Goal } \\
\hline Bridging & Market penetration & Market development \\
& Bridge for Share: & Bridge for Size: \\
& - ComAir* & - Delta* Swissair* Singapore \\
& British Airways, & Airlines, \\
& - SAS* Radisson Hotels & - SAA* Lufthansa, \\
& & - Northwest* KLM Airlines \\
\hline Bundling & Bundle for Share: & Bundle for Size: \\
& - American Airlines & - Marriott* Pizza Hut, \\
& *Hertz Car Rental* & - SAS Hotels*McDonalds \\
& Hilton Hotels. & \\
& - McDonalds* Coca Cola & \\
\hline
\end{tabular}


Cola which aims for increased consumption of both companies' products by existing customers.

Finally, 'Bundle for Size' alliances are intended to develop new markets. They make sense where brands that are not currently used complementarily can be combined to encourage greater joint usage. Finding that pizza was a favorite room service menu item, Marriott Hotels and Pizza Hut Restaurants have formed a partnership, providing a valued menu item for Marriott guests, encouraging them to order room service, and giving access to the in-room dining market for Pizza Hut. In Europe, SAS Hotels and McDonalds co-operate for similar reasons, increasing the size of each firm's market by linking product-markets that were previously distinct.

\section{Determinants}

In the second stage of the process, within the context of the broader strategic decision, specifying market penetration versus market development goals of the firm, and bridging versus bundling motivations, structures are designed and specific partners are selected. It is at this stage that the benefits of a market-driven approach are the greatest. The nature and extent of customer usage complementarity offers the basis for defining a broad 'consideration set' of potential partners (Varadarajan \& Rajaratnam, 1986). Customer usage complementarity refers to the extent to which a firm shares common customers with prospective alliance partners. Customer usage complementarity is high when there is little overlap between the firm's customer base and those of potential partners. The nature and extent of firm complementarity then defines a narrower 'choice set' from which to select actual partners. Firm complementarity refers to the fit between partners' resources and skills, and is based on power and cultural compatibility. Firm complementarity is high when there is little overlap between the firm's skills and resources and those of potential partners. Partners may have different objectives, lack required skills or resources, or differ in cultural orientation (Geringer, 1988a; 1988b). Partner match offers the greatest opportunity for alliance effectiveness (Bucklin \& Sengupta, 1993).

Firm complementarity is reflected in cultural compatibility and bargaining power parity. Much has been written about cultural differences in international markets, and it is readily apparent that conflict may arise from differences in notions of accepted conduct or use of inconsistent symbols between societies. It must also be recognized, however, that organizations have their own notions of accepted behaviours, and that clashes between corporate cultures may have more immediate, and less recognized, impacts on alliance success (Barnes \& Stafford, 1993). A main theme in the writing on organizational culture and its impact on inter-organizational relations is the degree of similarity or dissimilarity between organizations (Hatch, 1993).

By bringing together different firms, alliances invariably create tension. Managers must be aware of the source of this tension, its potential negative consequences, and possible coping strategies for dealing with the unavoidable by-products of alliances (Parkhe, 1991). Socio-cultural forces can create differences in the perception and interpretation of phenomena, based on different cognitive styles (Abramson et al., 1993). Differences in home country environments, as reflected in government policies towards co-operation, industry structures, and institutional support systems, create differ. ences in expectations and experiences. Different corporate cultures, with unique ideologies and guiding values, may require alliance partners to restructure their norms and belief systems to deal with conflicts between power and parity, or between market share and profitability.

The relationship between cultural similarity and alliance success has two opposing effects. On the one hand, alliances between organizations with high cultural similarity may succeed due to a better fit and less friction. On the other hand, organizations with low cultural similarity may benefit from an 'invigorating' effect that cultural diversity brings. The issue has more to do with cultural compatibility than with similar. ity (Bucklin \& Sengupta, 1993).

In the literature on bargaining power, there are also conflicting arguments as to its effect on alliances. One point of view holds that a firm with high bargaining power, whether on account of superior products, internal resources, market position or technological skills, can use that position to its advantage. A stronger firm is able to position itself at the hub of a web of parallel relationships (Harrigan, 1988), each clearly targeted and focussed. Without bargaining power, strategic relationships are very risky and difficult to manage effectively. Power allows the firm to raise the costs to its partners of infidelity, either through up-front demands or through dissolution penalties. As a consequence, firms are more likely to use equity joint ventures rather than contractual arrangements when conducting joint R\&D (Osborn \& Baughn, 1990). The reasons are that deeper relationships facilitate information flow, align the interests of the parties, and provide for day-to-day co-ordination.

The opposing point of view is that firms have been found to develop their production bases through alliances with partners of different size, and strengthen their knowledge bases through alliances with partners in the same subject areas (Hakansson, Kjellberg \& Lundgren, 1993). Empirical evidence on this issue suggests that

'imbalances in power and in managerial resources that each partner provides are significant drawbacks to alliance operations and, as organizational theorists predicted, have an important role in limiting alliance success' (Bucklin \& Sengupta, 1993: 43).

As such, bargaining power parity can be said to have an effect on partner selection and alliance success.

Success at the second stage, leads to enhanced performance in the third stage, when the desired alliance must be implemented and monitored. Many scholars have examined the question of management of ongoing relationships (Killing, 1982; 1983). Marketing writers in particular have been concerned with conflict and co-ordination in channels of distribution (Stern \& Reve, 1980; Dwyer, Schurr \& Oh, 1987). Others have identified the need for appropriate safeguards against partner opportunism to be put in place (Day \& Klein, 1987; Heide \& John, 1988). Much of the difficulty that arises in the third stage may be attenuated by more appropriate partner selection in the preceding stage. The more appropriate a relationship - the better the fit with its environment - the greater will be its success. The conditions determining 
appropriateness reflect environmental contingencies, both internal and external to the organization.

\section{Contingency model}

In the previous section, alliance strategies were classified into four types. Now, we show how different partners are appropriate for each type, embodying the Strategy-Structure linkage. Customer usage complementarity and firm complementarity are the two variables defining appropriateness. While choosing the most appropriate alliance does not guarantee success, it is a necessary prerequisite. The propositions are summarized in Table 2 which lists the partner selection criteria for each alliance type. Developing skills in managing alliances, required for successful implementation, is addressed by Spekman et al. (1996).

\section{Customer usage complementarity}

Analysis of customer usage complementarity is similar for bridging and bundling alliances. The conclusion, however, depends on the goal of the firm; whether market penetration or market development. As suggested by Varadarajan \& Rajaratnam (1986), an opportunity clearly exists for firms contemplating alliances to expand their market share and/or size by analyzing usage complementarity among related services. There is also evidence that a combination of brands with complementary attribute levels receives better evaluations than a brand extension (Park, Sung \& Shocker, 1996).

Gains in market share are achieved from increased purchases from existing customers in the market. Alliances reward customers for choosing to use the alliance products or services jointly, offering them better selection or greater convenience, coupled with lower transaction costs. In so doing, partners cement their relationships with existing customers and reduce brand switching. To achieve these goals, there must be existing commonality of customers between a firm and its prospective partners.

\section{Proposition I}

To achieve market penetration goals, firms should select alliance partners with whom there is low customer usage complementarity.

Market size is increased by reaching new customers and attracting them into the market. Low levels of cross-usage make it possible for firms to identify growth opportunities in new markets and focus attention on the challenges of under-

\begin{tabular}{|c|c|c|c|c|}
\hline & \multicolumn{4}{|c|}{ Strategy } \\
\hline & \multicolumn{2}{|c|}{$\begin{array}{c}\text { Market penetration } \\
\text { (share) }\end{array}$} & \multicolumn{2}{|c|}{$\begin{array}{c}\text { Market development } \\
\text { (size) }\end{array}$} \\
\hline & Bridging & Bundling & Bridging & Bundling \\
\hline Customer & Low & Low & High & High \\
\hline Usage & (P1) & (PI) & $(\mathbf{P} 2)$ & $(\mathbf{P} 2)$ \\
\hline \multicolumn{5}{|l|}{ Complementarity } \\
\hline Firm & High & Low & High & Low \\
\hline Complementarity & (P3) & (P4) & (P3) & (P4) \\
\hline
\end{tabular}

standing how the new markets operate. If usage complementarity were low (high overlap), there would be little incremental benefit as few additional customers would be gained and new markets would not be developed.

\section{Proposition 2}

To achieve market development goals, firms should select alliance partners with whom there is high customer usage complementarity.

\section{Firm complementarity}

While customer usage complementarity determines the 'consideration set' for prospective alliance partners, firm complementarity defines the 'choice set'. Usage is a necessary but not sufficient condition for partner selection. In domesticated, or administered markets the identity of the buyer and seller matters to the transaction. Anonymity is given up in exchange for reciprocity. Such markets are characterized by relational contracting (Macneil, 1978), where negotiations are internalized in the relationship, rather than settled anonymously in the market. Domesticated markets are not devoid of conflict or competition; these are inevitable when the goals of different parties are not fully congruent. However, the locus of conflict resolution resides in the interdependencies between the parties, and not in a neutral equilibrating market system. Hence, the management of coalitions is a key function of management, and the heart of strategic decision-making.

In a strategic alliance, firms co-operate based on mutual need and share the risks to reach a common goal (Lewis, 1990). Alliances depend on relationships, but mutual reliance means mutual vulnerability. For most firms, alliances represent significant problems of management. They bring together different parties with different cultures and bargaining power. Alliances raise the possibility of conflict between the parties, and risks of dependence on one another. They also bring about new problems in performance evaluation. It is often difficult to establish whose performance should be measured, to agree on the appropriate time-frame for evaluation, and to make trade-offs between partners' divergent interests.

The appropriate level of firm complementarity varies according to whether the alliance is bridging or bundling. An understanding of the appropriate level of firm complementarity can be found in transaction cost reasoning (Williamson, 1985). The logic behind bridging alliances is to close gaps in product-market coverage. By definition, appropriate partners have different skills and resources. Cultures and bargaining power should thus be complementary rather than overlapping factors in bridging alliances. Under such circumstances, which involve the creation of transaction-specific assets, we would expect high transaction costs to be a risk. The risks of opportunism, however, are mitigated by the product-market knowledge that the firm already has developed, based on an understanding of its own resources and skills. It is thus well able to monitor the activities of its partners, and avoids the control losses that would otherwise accrue.

\section{Proposition 3}

In bridging alliances, firms should select alliance partners with whom there is high complementarity, based on cultural differences and asymmetric power bases. 
The essence of a bundling strategy is learning about new products and delivering complementary benefits to one's customers. In contrast to the bridging case, however, with a bundling approach the firm cannot easily avoid or detect opportunistic conduct and, despite the learning benefits foregone, must select partners with whom there is high overlap of skills and resources. This low complementarity, whose purpose is largely defensive, could arise from either similar cultural perspectives or equal bargaining strengths. The former similarity provides reassurance of common values, while the latter ensures higher penalties for inappropriate conduct.

\section{Proposition 4}

In bundling alliances, firms should select alliance partners with whom there is high complementarity, based on cultural similarity and bargaining power parity.

\section{Illustration}

In the airline industry we have observed the formation of many alliances in the last few years, some cemented by equity exchanges. Some European airlines, such as SAS and British Airways, have announced that alliances are central to their basis of future competition. Most, if not all, of these airlines have publicly stated that their primary objective is to increase market presence both in terms of share and size. When examining this picture of a growing web of airline alliances, a number of questions come to mind: are all of these alliances appropriate? Are some of the relationships more likely to succeed than others? How can partner selection decisions be made with greater probability of better performance?

While lack of data on customer usage complementarity and firm complementarity, both before and after these alliances were formed, prevent us from testing the specific propositions, we find tentative support from anecdotal evidence that alliance formation is consistent with the propositions advanced above. For example, in investigating the KLM-Northwest Airlines alliance, Business Week (1992) reported that KLM badly needed the United States feed that Northwest could provide and struggling Northwest needed help as well; that is, a bridging alliance made sense. Similarly, it was reported that Northwest set out to change its image for lousy service and top flight service was KLM's forte; indicating high firm complementarity. This alliance, though strategically sound, however, is encountering serious problems in implementation. The two airlines have dragged their feet on linking flights, which would help them feed transatlantic passengers to one another instead of to competitors. Over time, one would expect this alliance to come under increasing strain as Northwest improves its service image.

In the Delta, Singapore and Swissair alliance, the stated goal was 'a seamless relationship for the consumer'. Despite some successes, the alliance is showing signs of strain. Delta has been reluctant to bring its partners into its terminal at Los Angeles International Airport, and is seen by its partners as dragging its feet (Foley \& Yoffie, 1994). The strain in the alliance may be explained in terms of the model developed above. In 1989, when the alliance was formed, Delta had little international presence, serving only a few locations in Europe from secondary markets in the US, and was looking desperately to develop new markets. In 'Bridge for Size' alliances, we proposed partners with high customer usage complemen. tarity (P2) and high firm complementarity (P3). From Delta's perspective, both Swissair and Singapore Airlines fit these requirements well. Both of the latter carriers had high quality images, strong service reputations, extensive international route structures, and brought European and Asian customers, all very different from Delta in the United States. Learning would be enhanced from Singapore Airline's low-cost structure and Swissair's cultural understanding.

By the early 1990s, however, Delta's strategy had changed, and so had the characteristics of desirable partners. In 1992 Delta acquired PanAm's European routes, and began to compete more directly with Swissair. Delta's objective became one of market penetration to restore profitability to PanAm's ailing route structure. Appropriate partner characteristics in 'Bridge for Share' alliances include low customer usage complementarity (P1), making Singapore Airlines a less desirable partner. Because the focus is still on bridging alliances, high firm complementarity remains desirable. According to our model, we would expect to see Delta form new relationships characterized by less customer usage complementarity, namely more customer overlap. Recently, in fact, Delta has announced a new link-up with Swissair, Sabena and Austrian Airlines to improve its market bridging capabilities. Due to PanAm's previous presence in Europe, these carriers share more customers with Delta than do Asian carriers. The logic behind the new alliance is to be able to carry passengers from most American cities to Europe, Asia and Africa on a single ticket.

\section{Conclusion}

Because of their prevalence in globalizing markets, coalitions and alliances are topical managerial issues. A stronger focus on non- or quasi-market behaviour is sorely needed at this time. The phenomenon of co-operative activity carries implications for broadened paradigms of business behaviour. Simply regarding these alliances as evidence of monopoly power ignores their efficiency motivations in competitive markets. Such strategic alliances should be seen in the context of the pursuit of sustainable competitive advantage (Day \& Wensley, 1983). The use of non-market and quasi-market arrangements to achieve such advantage is of major importance. These arrangements reflect strong efficiency considerations and the changing scope of the competitive arena. The formation of co-operative arrangements often entails the shifting of competitive activity from one dimension to another.

Conceptualizing strategic alliances from a market-driven perspective is useful because it suggests specific guidelines for setting objectives and for partner selection, and identifies areas where research can be useful in assisting managerial decision making. Two important points emerge from such a conceptualization. First, managers should take a broad view of strategic alliances and recognize the various effects they have on consumer purchase behaviour, as well as how interfirm relationships affect more traditional measures such as market share. Second, managers must realize that the long-term success of marketing programs is greatly affected by the potential inherent in an organization's strategic alliances. Simply stated, because the structure of strategic alliances will 
influence the effectiveness of all future marketing strategies, managers must understand how their marketing alliances affect consumer purchase behaviour and thus market share.

Managers need a more complete understanding of the purchase behaviour of their customers as a basis for making better strategic decisions about target market definition and product positioning, as well as selection of partners for strategic alliances. Perhaps a firm's most valuable asset for increasing market share is knowledge regarding its customers' usage of other brands in the same product class, as well as in complementary and substitute product classes (Bessen, 1993). New products developed or marketed through product-based alliances have little chance of success if no additional value is created for the customer or if managers do not know how to exploit the value of their market potential by developing profitable alliances. With the elaborate web of alliances developing in many industries, the appropriateness of partner selection will no doubt have an impact on alliance success.

A final issue deals with marketing's contribution to the dialogue on strategic alliances. By conceptualizing strategic alliances from a market-driven perspective and incorporating the central role of customers and erstwhile competitors, marketers are able to contribute more effectively to this discussion by surfacing issues relating to co-operative strategies, superior customer value creation, and relationship marketing (Day, 1992).

\section{Future research}

Complementarity in usage patterns and in firm capabilities offers a powerful way to conceptualize and develop symbiotic relationships or strategic alliances. Designing alliances in terms of which partner to choose depends on whether the objective is market penetration or market development and whether the alliance is intended to bridge gaps in productmarket coverage or to bundle complementary goods and services. Ultimate effectiveness of this method can be evaluated by comparing pre- and post-alliance penetration and share measures. Despite the lack of data to fully substantiate our method, there is a compelling theoretical rationale for the argument presented. We hope to see future research providing empirical support for the propositions that have been advanced.

\section{Acknowledgement}

Partial support for this research was provided by the Cornell Center for Hospitality Research.

\section{References}

Abramson, N., Lane, H., Nagai, H. \& Takagi, H. 1993. A comparison of Canadian and Japanese cognitive styles: implications for management interaction, Journal of International Business Studies, 24: 575-588.

Adler, L. 1966. Symbiotic marketing, Harvard Business Review, 44: 59-71.

Anderson, E. 1990. Two firms, one frontier: assessing joint venture performance, Sloan Management Review, Winter: 19-30.

Ansoff, I. 1957. Strategies for diversification, Harvard Business Review, $35: 114$

Arndt, J. 1979. Toward a concept of domesticated markets, Journal of Marketing, 43: 69-75.
Badaracco, J. 1991 The knowledge link: how firms compete through strategic alliances. Boston, MA: Harvard Business School Press.

Bames, J. \& Stafford, E. 1993. Strategic alliance partner selection: when organization cultures clash. In Cravens, David W. \& Dickson. Peter R. eds. Enhancing knowledge development in marketing. Chicago: American Marketing Association: 424-433.

Beamish, P. \& Banks, J. 1987. Equity joint ventures and the Theory of the Multinational Enterprise, Journal of International Business Studies, 18: 1-16.

Bessen. J. 1993. Riding the marketing information wave, Harvard Business Review, 71: 150-160.

Bleeke, J. \& Ernst, D. 1995. Is your strategic alliance really a sale? Harvard Business Review, 73: 97-106.

Bucklin, L. \& Sengupta, S. 1993. Organizing successful co-marketing alliances, Journal of Marketing, 57: 32-46.

Burgers, W., Hill, C. \& Kim, W. 1993. A theory of global strategic alliances: the case of the global auto industry, Strategic Management Journal, 13: 419-432.

Business Week. 1992. KLM-Northwest: three years and barely afloat, August 24: 61.

Byrne, J., Brandt, R. \& Port, O. 1993. The virtual corporation, Business Week, February 8: 98-102.

Day, G. 1992. Marketing's contribution to the strategy dialogue, Journal of the Academy of Marketing Science, 20: 323-329.

Day, G. 1995. Advantageous alliances, Journal of the Academy of Marketing Science, 23(4): 297-300.

Day, G. \& Klein, S. 1987. Cooperative behavior in vertical markets: the influence of transaction costs and competitive strategies. In Houston, Michael J. ed. Review of Marketing, WHERE: AMA.

Day, G. \& Wensley, R. 1983. Marketing theory with a strategic orientation, Journal of Marketing, 47: 79-89.

Dev, C. \& Klein, S. 1993. Strategic alliances in the hotel industry, Comell Quarterly, February: 42-45.

Dwyer, R., Schurr, P. \& Oh, S. 1987. Developing buyer-seller relationships, Joumal of Marketing, 51: 11-27.

Farquhar, P., Han, H. ,Herr, P. \& ljiri, Y. 1992. Master brands, Marketing Research, 4: 32-40.

Fisk, G. 1987. Competition and cooperation: paradigms, metaphors and theories for macromarketing policy analysis, Twelfth Annual Macromarketing Seminar. Montreal, Canada: August 6-9.

Foley, S. \& Yoffie, D. 1994. Swissair's alliances (B), 1991-1994. Case \# 9-794-153. Boston, MA: Harvard Business School Publishing.

Francese, P. 1994. President of American demographics. Conversation with the authors. February 11.

Franko, L. 1971. Joint venture divorce in the multinational company, Columbia Journal of World Business, May-June: 13-22.

Geringer, J. 1988a. Partner selection criteria for developed country joint ventures, Business Quarterly, Summer: 55-62.

Geringer, J. 1988b. Selection of partners for international joint ventures, Business Quarterly, Autumn: 31-36.

Gundlach, G. \& Murphy, P. 1993. Ethical and legal foundations of relational marketing exchanges, Journal of Marketing. 57: 35-46.

Hakansson, P., Kjellberg, H. \& Lundgren, A. 1993. Strategic alliances in global biotechnology - a network approach, International Business Review, 2(1): 83-96.

Hamel, G. 1992. Competition for competence and inter-partner learning within inter-national strategic alliances, Strategic Management Journal, 12: 83-103.

Harbison, J. \& Pekar, P. 1994. A practical guide to alliances: leapfrogging the learning curve. Boston, MA: View-Point-Booz. Allen and Hamilton.

Harrigan, K. 1988. Strategic alliances and partner asymmetries. In Contractor, Farok J. \& Lorange, Peter, eds. Cooperative Strategies in International Business. Lexington, MA: Lexington Books. 
Hatch, M. 1993. The dynamics of organizational culture, Academy of Management Review, 18(4): 657-693.

Heide, J. \& John, G. 1988. The role of dependence balancing in safeguarding transaction-specific assets in conventional channels, Joumal of Marketing, 52: 20-35.

Hotels. 1996. Bold steps by SAS, January 18.

Jarillo, J. 1988. On strategic networks, Strategic Management Journal, 9: 31-41.

Jennings, M. 1991. Still going global, Airline Business, August: 4042.

Killing, J. 1982. How to make a global joint venture work, Harvard Business Review, 60: 120-127.

Killing, J. 1993. Strategies for joint venture success. New York, NY: Praeger.

Levine, J. \& Byrne, J. 1986. Corporate odd couples, Business Week, July $21: 100-105$.

Lewis, J. 1990. Partnerships for profit: structuring and managing strategic alliances. New York, NY: Free Press.

Macneil, I. 1978. Contracts: adjustment of long term economic relations under classical, neoclassical, and relational contract law, Northwestern University Law Review, March: 854-906.

Miles, R. \& Snow, C. 1978. Organizational strategy, structure, and process. New York, NY: McGraw Hill.

Miles, R. \& Snow, C. 1986. Organizations: new concepts for new forms, California Management Review, 28: 62-73.

Ohmae, K. 1989. The global logic of strategic alliances, Harvard Business Review, 67: 143-154.

Oliver, C. 1990. Determinants of interorganizational relationships: integration and future directions, Academy of Management Review, 15(2): 241-265.

Osborn, R. \& Baughn, C. 1990. Forms of interorganizational governance for multinational alliances, Academy of Management $R e$ view, 33(3): 503-519.

Park, C., Jun, Y. \& Shocker, A. 1996. Composite branding alliances: an investigation of extension and feedback, Journal of Marketing Research, 33: 453-466.
Parkhe, A. 1991. Interfirm diversity, organizational learning, and longevity in global strategic alliances, Journal of International Business Studies, 34.

Parkhe, A. 1993. Strategic alliance structuring: a game theoretic and transaction cost examination of interfirm cooperation, Academy of Management Journal, 36: 794-829.

Perlmutter, H. \& Heenan, D. 1986. Cooperate to compete globally, Harvand Business Review, 64: 136-152.

Porter, M. 1990. Competitive strategy. New York, NY: The Free Press.

Rangan, U. \& Yoshino, M. 1996. Forging alliances: a guide to top management, The Columbia Journal of World Business, 31: 6-13.

Ring, P. \& Van de Ven, A. 1994. Developmental processes of cooperative interorganizational relationships, Academy of Management Journal, 19: 90-118.

Spekman, R. \& Sawhney, K. 1990. Toward a conceptual understanding of the antecedents of strategic alliances, Marketing Science Institute, Report No. 90-114.

Spekman, R., Isabella, L., MacAvoy, T. \& Forbes, T. 1996. Creating strategic alliances which endure, Long Range Planning, 29(3): 346-357.

Stern, L. \& Reve, T. 1980. Distribution channels as political economies: a framework for comparative analysis, Journal of Marketing, 44: 52-64.

Thorelli, H. 1986. Networks: between markets and hierarchies, Strotegic Management Journal, 7: 37-51.

Varadarajan, P. \&. Cunningham, M. 1995. Strategic alliances: a synthesis of conceptual foundations, Journal of the Academy of Mar. keting Science, 23(4): 282-296.

Varadarajan, P. \& Rajaratnam, R. 1986. Symbiotic marketing revisited, Journal of Marketing, 50: 7-17.

Willard, G., Schoenecker, T. \& Kreuger, D. 1990. Allegis Corp. -, 1987, Proceedings of the North American Case Research Associa. tion, 4: 90.

Williamson, O. 1985. The economic institutions of capitalism. New York, NY: Free Press. 